\title{
Three Taiwanese Scholars on the Problem of the Human Initial Notes
}

\author{
Valery Kiselev ${ }^{1, *}$ Wei-Ding Tsai ${ }^{2, a}$ \\ ${ }^{1}$ Department of History of Philosophy, RUDN University, Moscow, Russia \\ ${ }^{2}$ Department of Philosophy, National Chengchi University, Taipei, Taiwan, China \\ amail: sprache@nccu.edu.tw \\ *Corresponding author. Email: kiselev-va@rudn.ru
}

\begin{abstract}
The article examines the anthropological views of the three Taiwanese scholars: Hu Shih, Mou Zongsan and Xu Fuguan. They belong to different sectors of the ideological spectrum: Hu Shih was a representative of liberal thought, while Mou Zongsan and Xu Fuguan made a great contribution to the formation of contemporary Confucianism. These three philosophers are united not only by the refusal to recognize the Marxist ideology, but also by the desire, in the face of a severe spiritual crisis in Chinese culture, to modernize Chinese thought, preserving its traditional specificity and uniqueness. In their works there were formed special views on the problem of the human in the frame of the synthesis of Western and Chinese thought.
\end{abstract}

Keywords: History of philosophy, Chinese philosophy, Taiwanese philosophy, Hu Shih, Mou Zongsan, Xu Fuguan.

\section{INTRODUCTION: TAIWANESE PHILOSOPHY}

While defining Taiwanese philosophy, we primarily use territorial and cultural characteristics. Taiwanese philosophy is a philosophy that exists and develops on the geographical territory of the island of Taiwan and is based primarily on various concepts of Chinese classical philosophy and Chinese Buddhism.

Within the framework of the present study, issues of politics, administrative division, statehood, etc. are not considered. At the same time, we see that Taiwanese philosophy differs from the Chinese one. This fact is due to the historical peculiarities of the existence of this region (remoteness from the administrative and cultural center, the long-standing influence of Western culture, Japanese occupation, a special position in the context of the crisis of Chinese culture in the 20th century, etc.).

* The reported study was funded by RFBR and MOST according to research project N 20-511-S52002 "Philosophy of Being Human as the Core of Interdisciplinary Research".
The following stages in the development of intellectual thought in Taiwan can be distinguished:

- - the culture of Taiwanese aborigines (yuanzhumin, 原住民). It represents myths and legends. It cannot be considered either as philosophy or as protophilosophy;

- - the development of Confucian thought during the reign of the Ming and Qing dynasties;

- - the influence of Christian, primarily Protestant thought (Presbyterian Church in Taiwan was established by the end of the 19 th century);

- $\quad$ - the period of Japanese occupation (18951945);

- $\quad$ - modern period (after 1949).

At the end of the 19th - beginning of the 20th century there was an extremely unusual intellectual situation in China. Within a very short period, during only three decades, Chinese educated people became acquainted with the most prominent philosophical and socio-political teachings of the West. The books by Plato and Aristotle, Kant and 
Hegel, the evolutionary theory of Darwin, the doctrines of Nietzsche, Schopenhauer and others, were century after century replacing each other in the philosophical arena of Western civilization. But for China all these books and theories equally turned out to be "new" and expanding the views of the reading audience about the possibilities of theoretical reflection. At the same time Chinese intellectuals begin to think about the possibility of using the concepts of Western philosophy in Chinese thought [1].

In 1949, many thinkers who did not accept Marxist ideology immigrated to Taiwan. The focus of Chinese philosophical discussions shifted to the island, including discussions on the possibility of synthesizing Chinese thought with Western thought and a new ideal of a person.

These were both representatives of liberaldemocratic views (within the framework of this article we will consider the ideas of the most famous thinker in this direction, Hu Shih (18911962, 胡适)), and supporters of Confucianism, who became the founders of modern Confucianism, that appeared as a result of the synthesis of traditional Confucian thought with Western philosophical teachings (we will talk about the concepts of Mou Zongsan (1909-1995, 牟宗三) and Xu Fuguan (1903-1982, 徐复观)).

Despite the active use of Western methodology and theoretical tools, these thinkers remained Chinese, and their views were based on the ideas of Chinese classical philosophy.

\section{THE PROBLEM OF THE HUMAN}

Chinese thinkers (here mainly Confucian authors) were more interested not in questions "what is a person", but "what kind of a person is it", "what is the nature of the person". In this regard, the thought of Confucius gives an initial impetus to such reflection. Confucius himself said little about what a person is, or what the nature of a person is, leaning towards neutrality of a person. The followers of Confucius created a whole range of different views on human nature: good (Mengtzu), evil (Xun-tzu), good and evil (Gao-tzu), relative (Dong Zhongshu), etc. [2].

Since Antiquity the soul plays an important role in understanding the concept of a person in Western thought. The soul and body were opposed to each other, and one can find various forms of opposition and interaction between soul and body in the history of Western philosophy (Plato, Christianity, Descartes, etc.) [3].

In the Chinese tradition, there are a number of concepts (xin - 心, hunpo - 魂塊 etc.) that could be translated as "soul", but none of them corresponds in meaning and scope to the Western concept of the soul. In addition, Chinese thinkers believed that the soul is extremely closely related to the body [4]. And in solving the problem of a person, they have traditionally been worried about other issues, different from the Western ones.

At the end of the 19th - beginning of the 20th centuries China began to experience unprecedented pressure from the Western civilization. From primary borrowing in the field of military equipment and technologies, China gradually came to a comprehensive study of Western thought, including philosophical concepts. As a result, many thinkers strove to modernize traditional Chinese thought and find a modern interpretation of it. They tried to preserve the national specificity of Chinese philosophy (each of them did it in his own way) and to demonstrate its contemporary significance. They sought to prove the proportionality of Chinese philosophy to the Western one. As a result of this activity, reflection on the problem of a person was enriched with Western views but remained mainly in the sphere of traditional Chinese anthropology.

\section{HU SHIH - HOMO ERUDITUS}

$\mathrm{Hu}$ Shih had a great influence on the development of Chinese history, the history of philosophy and philosophy in the first half of the 20th century. His work was aimed mainly at showing existing problems in contemporary Chinese culture and suggesting solutions. Hu Shih himself noted that he became the founder, the forerunner in the Chinese science of an extremely, literally radically critical direction. In the introduction to the "Outline of the History of Ancient Chinese Philosophy", he noted that it is necessary to be extremely critical of historical and philosophical materials [5]. Hu Shih did not create a systematic concept of a person, but he was one of the first to try to combine Western and Chinese views on a human.

Critics called $\mathrm{Hu}$ Shih an extreme westernizer (quanpan xihua, 全盘西化) and saw the sources of his theories mainly in instrumentalism and Western views [6]. And it was not surprising, since, in fact, in the first half of the 20th century, a widespread opinion was to understand modernization precisely 
as westernization. The West seemed to be the only possible leading light for the movement towards modernity. Ideas of non-western modernization model will come later.

However, despite the fact that $\mathrm{Hu}$ Shih spoke extremely negatively about Confucianism and played a leading role in the "May Fourth Movement", he owes a great deal to Confucianism in terms of ideas about a human. For Hu Shih, a person is primarily a subject of education, i.e. one who receives education, studies, develops intellectually and spiritually.

In his works on education, $\mathrm{Hu}$ Shih paid great attention to traditional Chinese education. He demonstrated the importance of such education for the formation of an educated person, but at the same time he fiercely criticized this kind of education for its backwardness, inertia, and inability to modernize situation $[7,8]$.

Among educated people of that time, it was widely accepted that the only way out of the crisis for China were reforms, and that on the path of selfempowerment (ziqiang, 自强) China needed to learn from the West. Chinese intellectuals, especially those who studied abroad, first in Japan, then in Europe and in the United States, saw the power and wealth of those countries. They compared what they saw in China, with its backwardness and poverty, and understood that without reforms, China was going to die.

The situation was further complicated by the fact that in 1905 China abandoned the examination system, which determined the principles and direction of education for centuries. On the one hand, this fact simplified the opportunities for the development of new education, on the other hand, it deprived China of a ready-made system for training and selection of management personnel, and most importantly, it destroyed the ideal of an educated person that had developed over 1300 years. Within the framework of Confucian thought and the examination system, it was clear what a person should be, what he should do in order to be educated, and thus to be in demand by the state system and, as a result, to reach the goal of "being human". After the abolition of the exam system, the answer to the question "what a person should be" became less obvious.

$\mathrm{Hu}$ Shih saw the answer in the development of modern education that would combine the best aspects of Western and Chinese education [9, 10, $11]$.

\section{MOU ZONGSAN - KANTIAN REINTERPRETATION OF CHINESE PHILOSOPHY}

In 1958, Mou Zongsan was one of the coauthors of the famous "A Manifesto for a Reappraisal of Sinology and Reconstruction of Chinese Culture" (为中国文化敬告世界人士宣言). This manifesto refuted the idea that the Chinese culture was dead. The authors of the manifesto agreed that the Chinese civilization was in deep crisis, but at the same time they urged to treat it as a sick person, i.e. with care, with a desire to help to recover.

Mou Zongsan's views are a prime example of the intellectual synthesis of the traditional Chinese thought (Confucianism) and Western philosophy. Mou Zongsan's concepts are more philosophical (than those of $\mathrm{Hu}$ Shih) in terms of their metaphysics. He based his ideas on the most metaphysical views of Chinese thought (the LuWang school), and supplemented their reading with the use of Kant's ideas. According to Mou Zongsan himself, his views are moral metaphysics. The Chinese philosopher sought, in the spirit of Kant, to explore pure non-empirical principles regardless of experience.

At the same time, the Chinese thinker was not a consistent Kantian, but used the ideas of the German philosopher as a tool to strengthen and modernize Chinese thought. He did not agree with Kant in everything, both ideologically and because of the peculiarities of the Chinese culture. For example, he noted that "Kant speaks only of moral theology and does not speak of moral metaphysics. "Moral" is used as an adjective in the sense that theology and metaphysics are based on morality. While the Confucians talk about moral metaphysics, they do not talk about moral theology, because Confucianism is not a religion" [12].

Mou Zongsan regarded Confucianism as a spiritual moral philosophy that fulfilled the basic functions of religion. For this reason, it may sometimes seem that Confucianism is a religion, but Mou Zongsan insisted that it cannot be viewed as a religion in the ordinary sense of the word [13, $14]$.

Highlighting the peculiarities of the Chinese thought, Mou Zongsan noted that in the ancient philosophical texts "The Book of Changes" and "Zhong Yong", Heaven was considered as the highest reality, it was a creative spirit that recreated all that existed. At the same time, Heaven was 
intrinsically inherent in man as an innate moral nature - a moral reason. Thus, the natural order was viewed by Mou Zongsan in the traditional Chinese way as a transcendental moral order. In this sense, Mou Zongsan continued the ideas of the Lu-Wang school, which said that "Reason is a principle" (xin $j i l i$, 心即理), and thus equated the transcendental moral reason and the heavenly principle [12]. For Lu Jiuyuan, recognition of the unity of subject and object was essential. Within the framework of this unity, both the subject and the object are a complete analogue of each other. Since all "principles" are contained in the heart, which can be interpreted as the psyche, all knowledge is directed inward, and morality is thus recognized as autonomous [15].

The central category of Mou Zongsan's metaphysics is transcendental moral reason. The Chinese thinker associated this category with many ideas of both Chinese and Western thought, for example, the heart and human nature of Mencius, the pure knowing (liangzhi, 良知) of Wang Yangming, the free will of Kant [12]. It should be noted that mixing different terms without contradiction is typical for the Chinese thought. Western scholars studying Chinese thought, and in particular the views of Mou Zongsan, try to distinguish and separate terminology, for example, "moral creative reality, which is reason" and "moral creative reality, which is human nature" [12].

Developing the classical Confucian understanding of human nature, Mou Zongsan noted that it is the moral reason that is a human nature, both of them are the moral creative reality granted by Heaven and identical to the heavenly. A person needs to realize moral reason through moral practice, in this way he realizes heavenly reality (principle) [12].

In the moral mind, according to Mou Zongsan, there is a mutual realization of empathy and intellectual intuition, which ultimately produces an intuitive moral knowledge that makes moral creativity possible. In the realization of a moral reason, a person is able to unite with the world, with the myriad of things. And in the comprehension of wisdom, spiritual union with heaven in virtue is possible [12].

A person, according to Mou Zongsan, has internal sage (neisheng, 内圣, being sage inside). For Mou Zongsan, the human mind is dual, it consists of moral reason (inborn moral consciousness - inner wisdom) and ordinary mind. They are different, but inseparable [12].

\section{XU FUGUAN - PHILOSOPHY AS ANXIETY}

$\mathrm{Xu}$ Fuguan did not build his own philosophical system. His work was primarily directed towards a modern interpretation of traditional Chinese thought. He sought to reinterpret Confucian positions in accordance with the development of modern, primarily Western, thought.

$\mathrm{Xu}$ Fuguan compared the features of Chinese and Western thought and, within the framework of the Chinese tradition, defined Chinese thought as a manifestation of the Chinese humanistic spirit. He distinguished between the origins of the Chinese and Western thought. He recognized curiosity as beginning of Western philosophy, while the beginning of the Chinese philosophy they saw in anxiety, uneasiness.

Initially, the development of all civilizations began with a fear of deities (which manifested itself in the emerging mythological consciousness). But further, the paths of civilizations diverged, and unique features inherent in individual civilizations appeared. According to Xu Fuguan, it is the feeling of anxiety, and not the search for knowledge or curiosity, that determines the focus of Chinese thought on self-knowledge and moral virtue. Feelings of anxiety are not just fear, but a sense of responsibility that requires overcoming difficulties on your own [16].

As another feature of the Chinese culture, $\mathrm{Xu}$ Fuguan singled out the focus on the cultivation of the mind (xin, 心, heart). The special ethical system of Chinese thought is based on this, he considered. In this idea he followed Mencius' concept of the goodness of a human nature. At the same time, $\mathrm{Xu}$ Fuguan developed the peculiarities of the perception of a person as a unity of body and spirit [16].

For the Chinese thinkers, the body is not just a matter or mechanism. A man and the human body are parts of the universe, the connecting link of the heaven-man-earth triad (tian-ren-di, 天人地), where " tian-di" means "space / cosmos" (literally, heaven-earth), and "ren" is "man". To achieve moral perfection and character transformation, it is necessary to participate in the process of "restoring bodily experiences" [17]. 
In the field of political philosophy, Xu Fuguan strongly opposed communist ideology. As a Confucian, he did not share traditional imperial views, he saw elements of liberalism in Confucianism, e.g. freedom, etc. At the same time, $\mathrm{Xu}$ Fuguan opposed liberal thought and did not consider it suitable for the Chinese culture. China's future, both cultural and political, he saw in the development of Confucianism.

\section{CONCLUSION}

Taiwanese philosophy is a unique and distinctive direction in the development of Chinese philosophy. The peculiarities of the development of Taiwanese philosophy in the second half of the 20th century were determined by the special conditions of its existence. First of all, thinkers of that time were concerned about such issues as the weakness of China in relation to the West and the threat to the existence of the Chinese tradition, the spread of Western thought, forms of government and way of life. In their work, they tried to create a new image of China and Chinese thought, and thus an ideal of a person who would be able to conduct a dialogue with the West on an equal footing. $\mathrm{Hu}$ Shih, Mou Zongsan, and Xu Fuguan had different intellectual backgrounds, shared different values and ideals, and were influenced by different Western intellectual systems. Nevertheless, in their works, one can see an attempt to combine the classical Chinese understanding of a person with different Western views, for the sake of a great goal, which was to preserve the unique features of Chinese national thought in the modern world, to preserve not as a museum exhibit, but as a living element of the modernity.

\section{AUTHORS' CONTRIBUTIONS}

Valery Kiselev and Wei-Ding Tsai together developed the conception of the research, gathered research materials, made analysis of the texts by $\mathrm{Hu}$ Shih, Mou Zongsan and Xu Fuguan and wrote the manuscript. Wei-Ding Tsai translated corresponding quotes from Chinese into English. Valery Kiselev made translation of the whole article into English.

\section{REFERENCES}

[1] Yunzhi Geng. The Introduction to Study Cultural Transformations of China in Modern Times. Chengdu: Sichuan renmin chubanshe, 2008.
[2] Wing-tsit Chan. A Source Book in Chinese Philosophy. Princ.: Princeton University Press, 1963, pp. 271-288.

[3] Conjunctions of Mind, Soul and Body from Plato to the Enlightenment. Ed. by Danijela Kambaskovic. Dordrecht: Springer, 2014.

[4] See: M.V. Rubets. Body perception in Chinese tradition. // Physicality as an epistemological phenomenon. M.: IFRAN, 2009, pp. 147-161.

[5] Shih Hu. Outline of the History of Ancient Chinese Philosophy. Beijing: Dongfang Chubanshe, 1996, pp. 7-8.

[6] Critics of $\mathrm{Hu}$ Shih. Vol. 1-8. Beijing: Shenghuo Dushu Xinzhi Sanlian Shudian, 1955.

[7] Shih Hu. About home education. // Hu Shih full collection of writings. Hefei: Anhui jiaoyu chubanshe, 2003. Vol. 20, pp. 3-5.

[8] Shih Hu. Materials for the History of Education in China. // Hu Shih full collection of writings. Hefei: Anhui jiaoyu chubanshe, 2003. Vol. 20, pp. 343-344.

[9] Shih Hu. Philosophy of Education of $\mathrm{J}$. Dewey. // Hu Shih full collection of writings. Hefei: Anhui jiaoyu chubanshe, 2003. Vol. 20, pp. 36-48.

[10] Shih Hu. About University Teaching System. // Hu Shih full collection of writings. Hefei: Anhui jiaoyu chubanshe, 2003. Vol. 20, pp. 57-60.

[11] Shih Hu. Student and Society. // Hu Shih full collection of writings. Hefei: Anhui jiaoyu chubanshe, 2003. Vol. 20, pp. 79-86.

[12] Zongsan Mou. Nineteen Lectures on Chinese Philosophy. Guiyang: Guizhou Renmin chubanshe, 2020, pp. 52, 189, 184-189, 198, 206, 245-246.

[13] See: Julia Ching. Confucianism and Christianity: A Comparative Study. New York: Kodansha International. 1978.

[14] See: Yong Chen. Confucianism as Religion. Leiden: Brill, 2012.

[15] A.I. Kobzev. Philosophy of Chinese NeoConfucianism. M.: Vostochnaya literature, 2002. 
[16] Fuguan Xu. Articles on the History of Chinese Thought. Shanghai: Shanghai shudian chubanshe, 2004, pp. 27-28.

[17] Tea Sernelj. The Unity of Body and Mind in $\mathrm{Xu}$ Fuguan's Theory. // Asian Studies II (XVIII), 1 (2014), pp. 83-95. 